\title{
Transfer factor, lung volumes, resistance and ventilation distribution in healthy adults
}

\author{
Sylvia Verbanck ${ }^{1}$, Alain Van Muylem², Daniel Schuermans ${ }^{1}$, Ivan Bautmans ${ }^{3}$, \\ Bruce Thompson ${ }^{4}$ and Walter Vincken ${ }^{1}$
}

Affiliations: ${ }^{1}$ Respiratory Division, University Hospital UZ Brussel, Vrije Universiteit Brussel, Brussels, Belgium. ${ }^{2}$ Respiratory Division, University Hospital Erasme, Université Libre de Bruxelles, Brussels, Belgium. ${ }^{3}$ Geriatrics Dept, University Hospital UZ Brussel, Vrije Universiteit Brussel, Brussels, Belgium. ${ }^{4}$ Allergy, Immunology and Respiratory Medicine, The Alfred Hospital and Monash University, Melbourne, Australia.

Correspondence: Sylvia Verbanck, Respiratory Division, University Hospital UZ Brussel, Laarbeeklaan 101, 1090 Brussels, Belgium.

E-mail: sylvia.verbanck@uzbrussel.be

ABSTRACT Monitoring of chronic lung disease requires reference values of lung function indices, including putative markers of small airway function, spanning a wide age range.

We measured spirometry, transfer factor of the lung for carbon monoxide (TLCO), static lung volume, resistance and ventilation distribution in a healthy population, studying at least 20 subjects per sex and per decade between the ages of 20 and 80 years.

With respect to the Global Lung Function Initiative reference data, our subjects had average z-scores for forced expiratory volume in $1 \mathrm{~s}$ (FEV1), forced vital capacity (FVC) and FEV1/FVC of $-0.12,0.04$ and -0.32 , respectively. Reference equations were obtained which could account for a potential dependence of index variability on age and height. This was done for (but not limited to) indices that are pertinent to asthma and chronic obstructive pulmonary disease studies: forced expired volume in $6 \mathrm{~s}$, forced expiratory flow, TLCO, specific airway conductance, residual volume (RV)/total lung capacity (TLC), and ventilation heterogeneity in acinar and conductive lung zones.

Deterioration in acinar ventilation heterogeneity and lung clearance index with age were more marked beyond 60 years, and conductive ventilation heterogeneity showed the greatest increase in variability with age. The most clinically relevant deviation from published reference values concerned RV/TLC values, which were considerably smaller than American Thoracic Society/European Respiratory Society-endorsed reference values.

@ERSpublications

We present reference equations for median and variability of most lung function indices, in the age range $\mathbf{2 0 - 8 0}$ years http://ow.ly/SsZFW

This article has supplementary material available from erj.ersjournals.com

Received: May 042015 | Accepted after revision: Sept 032015 | First published online: Nov 192015

Support statement: This study was supported by the Fund for Scientific Research - Flanders. Funding information for this article has been deposited with FundRef.

Conflict of interest: None declared.

Copyright OERS 2016 


\section{Introduction}

Studies in patients with asthma or smoking-induced lung disease require appropriate reference values to determine lung function abnormality, especially in the early stages of the disease process. While asthma can arise at any age, chronic obstructive pulmonary disease (COPD) usually develops later in life, yet both chronic conditions lead to follow-up periods of lung function potentially extending through old age. Both conditions are usually marked by a spirometric deficit which can now be set against reference equations that are valid worldwide $[1,2]$. However, the characterisation of asthma and smoking-induced lung disease can also benefit from lung function and ventilation distribution indices that are thought to be sensitive to two distinct but sometimes concomitant phenomena: peripheral airway abnormality and abnormal heterogeneity of airway function at all lung depths. Hence, clinical research studies regularly include indices dedicated to represent peripheral and heterogeneous airway function [3]. Abnormality of these lung function indices can sometimes be assessed by comparison with reference values, either obtained for a particular index obtained in one study population $[4,5]$ or based on reference equations constructed from the summary of previous equations [6]. To date, the most complete set of reference values acquired on a well-defined population ( $\mathrm{n}=179 ; 18-86$ years) is by ROBERTs et al. [7], since it includes spirometry, plethysmography, transfer factor of the lung for carbon monoxide (TLCO) and single-breath washout indices (phase III slope) on nonsmoking adults.

The main objective of this work was to provide easy-to-use reference equations on all lung function and ventilation indices that have proven to be relevant to asthma, COPD or cystic fibrosis (CF) to some extent in the past. On the lung function side, TLCO and the ratio of residual volume (RV) over total lung capacity (TLC) are particularly relevant to COPD and asthma. On the ventilation distribution side, indices of acinar and conductive ( acin, Scond) ventilation heterogeneity derived from the normalised phase III slope analysis of the multiple-breath washout (MBW) have been used to characterise bronchial hyperresponsiveness in asthma [8] or asthma control [9], or to pick up different stages of smoking-induced lung disease [10]. In more severe lung disease such as in patients with COPD or patients with CF, the lung clearance index (LCI) [11] and the curvilinearity (Curv) derived from the MBW concentration curve [12] may suffice to quantify degree of heterogeneity. Airway resistance is also seen to be increased in asthma and COPD, with values depending on the method (forced oscillation or plethysmography) [13] or the equipment used [14]. Even if most indices are bound to be partly apparatus- and method-dependent, the dependence of any physiological index on age and/or height will likely be similar across laboratories. Here, we aimed to obtain all the above indices on the same population, in the same lung function laboratory of the university hospital and coached by the same well-trained lung function technician.

\section{Materials and methods}

The study protocol was approved by the local UZ Brussel research ethics committee (B14320097554 and B143201112421 pertaining to data covering $\leqslant 65$ and $>65$ years age groups, respectively); selected spirometric and MBW indices from our centre have been published previously for the 25-65 years group [15]. Lung function and MBW tests were collected on healthy nonsmoking subjects with $<3$ pack-years (in case of ex-smokers) in the age range 20-80 years. All participating subjects were Caucasian, were required to have a body mass index $<33 \mathrm{~kg} \cdot \mathrm{m}^{-2}$ and were defined as healthy through clinical screening, with no medical history of respiratory disease. At least 40 subjects ( 20 males/20 females) were recruited per decade in the age range $20-80$ years, based on the recommended number of subjects described by QUANJER et al. [16]. We adapted the numbers needed to the age range under study here (20-80 years) where age dependency of most indices was expected to be monotonous, in contrast to what occurs in the age range $<20$ years [1]. However, because we anticipated different variability around the median in different age ranges for at least some indices, we applied generalised additive models for location, scale and shape method proposed by the Global Lung Function Initiative (GLI) $[1,2]$ to obtain LambdaMuSigma (LMS) model fits. From the resulting parameters L, M and S, predicted values and lower and upper limit of normal (LLN, ULN) can be readily computed; see example in online supplementary material.

All lung function measurements were performed in the same centre (centrally located in Belgium), by the same lung function technician, according to the American Thoracic Society (ATS)/European Respiratory Society (ERS) guidelines for lung function measurements [17] using commercial equipment (Vmax Encore VE models 20c, 22 and 22d; Cardinal Health, Dublin, OH, USA). After standard lung function testing including spirometry, TLCO, static lung volumes and airway resistance by body plethysmography, MBW tests were performed as previously described [15]. Volumes from all above-mentioned tests were reported at body temperature, ambient pressure, saturated with water vapour.

\section{Spirometry}

In each subject, three acceptable manoeuvres were performed that satisfied the reproducibility criteria of the ATS/ERS guidelines [18]. First, we selected the largest forced expired vital capacity (FVC), the largest 
forced expired volume in $1 \mathrm{~s}\left(\mathrm{FEV}_{1}\right)$ and the largest forced peak expiratory flow (PEF) obtained over the three blows. Then, we selected the blow with the largest sum of FEV1 and FVC, from which we extracted forced expired volume in $6 \mathrm{~s}$ (FEV6), forced expiratory flow at 75\% of FVC (FEF75\%) and forced expiratory flow at $25-75 \%$ of FVC (FEF25-75\%). Finally, derived indices FEV1/FVC and FEV1/FEV6 were considered for developing reference equations.

\section{Carbon monoxide transfer measurement}

Two acceptable tests were performed in each subject [19]. Using the single-breath technique and $21 \%$ $\mathrm{O}_{2} / 0.3 \% \mathrm{CO} / 0.3 \% \mathrm{C}_{2} \mathrm{H}_{2} / 0.3 \% \mathrm{CH}_{4}$ with balance $\mathrm{N}_{2}$ as the inspiratory gas mixture, we obtained TLCO, alveolar volume at total lung capacity $(V \mathrm{~A})$ and transfer coefficient of the lung for carbon monoxide $(\mathrm{KCO})$ (i.e. $T \mathrm{LCO} / V \mathrm{~A}$ ); all indices were reported as the mean of values obtained from both tests.

\section{Static lung volumes and resistance using body plethysmography}

Two acceptable tests were performed in each subject [20]. We retained the measurement of RV determined by whole-body plethysmography ( $R V_{\text {pleth}}$, functional residual capacity determined by whole-body plethysmography (FRCpleth), total lung capacity determined by whole-body plethysmography (TLCpleth), airway resistance (Raw) and specific airway conductance ( $\mathrm{s} G \mathrm{aw}$ ). All indices were reported as the mean of values obtained from both tests. To ensure extraction of proper FRCpleth values with the body plethysmograph model that we used (Vmax Encore 22d), values labelled in the report as "FRC" and "Vtg" (thoracic gas volume) were examined to determine whether FRC corresponded to the actual FRC level observed on the traces. This had to be done because biological calibrators and tests with two independent plethysmograph boxes had indicated an artefact in FRCpleth (despite proper RVpleth and TLCpleth). With our particular bodybox and its software settings this was due to an unpredictable volume drift upon closing the shutter valve, such that the relative levels corresponding to $V$ tg and FRC needed readjusting.

\section{MBW test}

A bag-in-box and valve system was used, with a re-inspired dead space (i.e. re-inspired volume in subsequent MBW inhalations) of $50 \mathrm{~mL}$ and a $\mathrm{N}_{2}$ analyzer (PK-Morgan, Chatham, UK). The MBW test involved 1-L tidal breathing from FRC. Three acceptable tests were performed in each subject. Each MBW test was analysed with a semi-automated break-point analysis [21] from which phase III slope and mean expired concentration were obtained for every breath. FRCmbw was obtained by mass balance including all breaths up to the one corresponding to mean expired concentration just under 1/0.40th of the initial $\mathrm{N}_{2}$ concentration. From three acceptable tests, data were cumulated to obtain plots of mean expired concentration and phase III slope versus lung turnover (TO; cumulative expired volume/FRCmbw for any given test). From the semi-log plot of mean expired concentration (as a percent of initial concentration) versus TO we derived: 1) LCI, as the TO value corresponding to the intercept between the semi-log plot of mean expired concentration and the 1/0.40th initial concentration level; 2) Curv, as unity minus the ratio of two regression slopes, where the regression slope in the denominator is that determined in the range $\mathrm{TO}=0$ and $\mathrm{TO}=\mathrm{LCI} / 2$ and in the numerator that between $\mathrm{TO}=\mathrm{LCI} / 2$ and TO=LCI [12]. From the plot of normalised phase III slope (normalised by mean expired concentration) versus TO, we derived indices of acinar and conductive (Sacin, Scond) ventilation heterogeneity, as well as two modified indices ( $\operatorname{acin}^{*}, S_{\text {cond }}{ }^{*}$ ) for use in patient groups such as CF where ventilation heterogeneity is so marked that Scond becomes invalid [22]. Finally, we determined Fowler dead space volume of the first breath $(V D F)$ in order to assess its potential impact on LCI when exploring the relationship between LCI, which is an overall index of ventilation heterogeneity, and its potential determinants (Sacin, Scond).

\section{Statistical analysis}

Simple comparison between selected indices, linear and stepwise multiple regressions were performed using MedCalc (version 14.8.1; MedCalc, Mariakerke, Belgium). For the regression equations, we followed the guidelines and procedures described in QuANJER et al. [1] and Lum et al. [23], using the GAMLSS package (version 4.3-4) in $\mathrm{R}$ (version 2.15.2; R Foundation, Vienna, Austria). After Box-Cox-Cole-Green transformation of the data, an LMS model fit was obtained that allows the median and spread of the distribution to vary with height and age (or age squared). We also included sex and tested for interaction between age and sex in the initial estimate of the median. For Curv, which had some zero values, the BoxCox-Cole-Green transformation required the addition of a very small positive value $(+0.001)$ to the actual Curv measurement value. With the Box-Cox-Cole-Green transformation, the obtained coefficients for $\mathrm{M}$ are to be used in a linear expression to obtain the predicted value, whereas the obtained coefficients for $\mathrm{S}$ are to be used in an exponential expression to obtain the spread; L corresponds to nu estimated by a constant coefficient. The LLN and ULN (5th and 95th percentile) can then be computed as M $\times(1-1.645 \times \mathrm{L} \times \mathrm{S})^{(1 / \mathrm{L})}$ and $M \times(1+1.645 \times L \times S)^{(1 / L)}$ [23]. Guided by the Schwarz Bayesian Criterion, the most suitable model with likely contributors was selected for each variable. In all the above analyses, statistical significance was accepted at $\mathrm{p}<0.05$. 


\section{Results}

The total cohort comprised of 252 subjects, who were homogeneously distributed over the six decades between 20 and 80 years, and over both sexes (figure 1a) and with maximum BMI just under $32 \mathrm{~kg} \cdot \mathrm{m}^{-2}$. To characterise our study population with respect to GLI2012, we determined z-scores for FEV1, FVC and FEV1/FVC based on the GLI2012 reference values for Caucasians [2]: mean ( \pm sD) z-scores for FEV1, FVC and FEV1/FVC were $-0.12( \pm 0.90),+0.04( \pm 0.85)$ and $-0.32( \pm 0.71)$, respectively. Table 1 summarises the mean \pm SD of all variables studied here.

For most variables, reference equations were constructed, resulting in coefficients for sex, height, and age and/or age squared to obtain L, M and S (table 2); an example computation of predicted, ULN and LLN is provided in the online supplementary material. Figure 2 shows the raw data and their LMS fit (median, LLN, ULN) for two lung function indices that are particularly relevant for studies in asthma and COPD: TLCO and RV/TLC. Figure 3 shows the raw data and their LMS fit for three relevant ventilation distribution indices: LCI, Sacin and Scond. In figures 2 and 3, left and right panels are, respectively, female and male data drawn to the same vertical axis; in order to be able to also plot the LMS fit for those indices that depend on height, height was taken into account in each sex group by use of the height-age relationships of figure 1(b). The raw data plots with superimposed LMS fit for all indices of table 1 and their colour-coded comparison to other reference values, wherever available $[4-7,24-30]$, are in the online supplementary material.

No reference equations were drawn up for FRCpleth and VA due to methodological considerations (see Discussion section), but these indices were compared with FRCmbw and TLCpleth, respectively (figure 4). A Bland-Altman representation of FRCmbw and FRCpleth showed good overall agreement, while VA consistently fell below TLCpleth (by $0.46 \mathrm{~L}$ ). Multilinear regression of LCI versus its potential contributors (Sacin, Scond, VDF/FRC and FRC) retained the first three indices, which together accounted for $58 \%$ of the LCI variability: partial correlation coefficients were +0.67 for $S$ acin $(p<0.0001),+0.13$ for $S$ cond $(p=0.04)$ and +0.20 for $\operatorname{VDF} / \mathrm{FRC}(\mathrm{p}=0.002)$.

\section{Discussion}

We have developed reference equations, LLN and ULN for indices derived from spirometry, TLCO, static lung volume, resistance and ventilation distribution tests. The lung function indices studied are directly relevant to common respiratory illnesses, including asthma, COPD and CF.

\section{Spirometry}

As GLI2012 already offers worldwide valid reference equations [1], we used these to verify that our subjects obtained $\mathrm{z}$-scores close to zero. The coefficients provided in table 2 for the most widely used indices already covered by the GLI, such as FEV1 and FVC, served to verify that the statistical methodology was sound and that the expected explanatory variables were obtained. We then produced reference equations for FEV6 and FEV1/FEV6 which have been suggested for use to screen smokers for restriction and obstruction in the primary care setting [31]. In the online supplementary figures S4 and S5, the LLN values for FEV6 and FEV1/FEV6 are seen to be close to those reported by HANKINSON et al. [24]; they almost coincide in the age range 45-65 years, i.e. the age category where screening for smoking-induced lung disease is probably most relevant. The diagnostic value of $\mathrm{FEF} 75 \%$ or $\mathrm{FEF} 25-75 \%$ in adults has been questioned in recent years, e.g. in terms of their added value with respect to other spirometric indices when classifying patients [32].
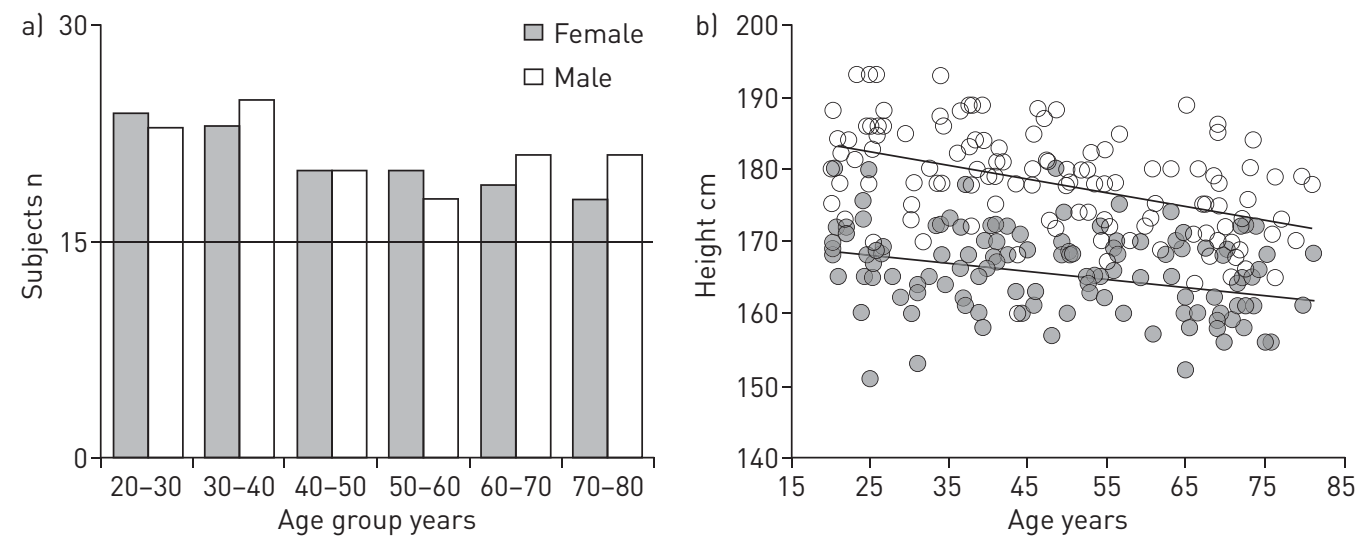

FIGURE 1 a) Histogram of subjects distributed across the different age categories in either sex. b) Scatterplots of height versus age in either sex group and their regression lines; corresponding regression equations for females: height $(\mathrm{cm})=-0.1133 \times$ age $($ years $)+171.16$ and for males: height $(\mathrm{cm})=-0.187 \times a g e($ years $)+186.97$. 
TABLE 1 Values of all parameters in the entire study population grouped by sex

\begin{tabular}{|c|c|c|}
\hline & Female & Male \\
\hline Subjects $n$ & 124 & 128 \\
\hline Height cm & $165.7 \pm 6.1$ & $177.8 \pm 7.2$ \\
\hline $\mathrm{BMI} \mathrm{kg} \cdot \mathrm{m}^{-2}$ & $22.9 \pm 3.1$ & $24.7 \pm 3.0$ \\
\hline \multicolumn{3}{|l|}{ Spirometry } \\
\hline FEV $1 \mathrm{~L}$ & $2.8 \pm 0.6$ & $3.9 \pm 0.8$ \\
\hline FVC L & $3.6 \pm 0.7$ & $5.0 \pm 1.0$ \\
\hline $\mathrm{FEV}_{1} / \mathrm{FVC}$ & $0.79 \pm 0.06$ & $0.78 \pm 0.05$ \\
\hline FEV6 L & $3.5 \pm 0.7$ & $4.9 \pm 1.0$ \\
\hline $\mathrm{FEV}_{1} / \mathrm{FEV}_{6}$ & $0.80 \pm 0.05$ & $0.79 \pm 0.05$ \\
\hline PEF L.S ${ }^{-1}$ & $6.6 \pm 1.2$ & $10.0 \pm 1.7$ \\
\hline FEF $25-75 \% L \cdot S^{-1}$ & $2.7 \pm 0.9$ & $3.6 \pm 1.2$ \\
\hline FEF $75 \% L \cdot S^{-1}$ & $1.2 \pm 0.6$ & $1.5 \pm 0.8$ \\
\hline \multicolumn{3}{|l|}{ Carbon monoxide transfer } \\
\hline$T \mathrm{LCO} \mathrm{mmol} \cdot \mathrm{min}^{-1} \cdot \mathrm{kPa}^{-1}$ & $7.1 \pm 1.3$ & $10.3 \pm 2.0$ \\
\hline $\mathrm{Kco} \mathrm{mmol} \cdot \mathrm{min}^{-1} \cdot \mathrm{kPa}^{-1} \cdot \mathrm{L}^{-1}$ & $1.52 \pm 0.22$ & $1.56 \pm 0.23$ \\
\hline VA L & $4.7 \pm 0.7$ & $6.6 \pm 1.0$ \\
\hline \multicolumn{3}{|l|}{ Body plethysmography } \\
\hline RV pleth L & $1.6 \pm 0.5$ & $1.9 \pm 0.7$ \\
\hline FRCpleth L & $3.0 \pm 0.6$ & $3.6 \pm 0.7$ \\
\hline TLCpleth L & $5.2 \pm 0.7$ & $7.0 \pm 1.0$ \\
\hline RV/TLC & $0.31 \pm 0.09$ & $0.27 \pm 0.09$ \\
\hline Raw kPa.s. $\mathrm{L}^{-1}$ & $0.26 \pm 0.06$ & $0.23 \pm 0.06$ \\
\hline $\mathrm{sGaw} L \cdot \mathrm{s}^{-1} \cdot \mathrm{kPa}^{-1}$ & $1.23 \pm 0.25$ & $1.23 \pm 0.28$ \\
\hline \multicolumn{3}{|l|}{ Multiple-breath washout } \\
\hline FRCmbw L & $2.8 \pm 0.5$ & $3.7 \pm 0.8$ \\
\hline VDF/FRC & $0.051 \pm 0.010$ & $0.049 \pm 0.010$ \\
\hline $\mathrm{LCl}$ & $6.5 \pm 0.6$ & $6.5 \pm 0.6$ \\
\hline Curv & $0.22 \pm 0.09$ & $0.21 \pm 0.09$ \\
\hline Scond $\mathrm{L}^{-1}$ & $0.036 \pm 0.017$ & $0.036 \pm 0.013$ \\
\hline Sacin $L^{-1}$ & $0.10 \pm 0.05$ & $0.12 \pm 0.05$ \\
\hline Scond* $L^{-1}$ & $0.046 \pm 0.022$ & $0.046 \pm 0.017$ \\
\hline Sacin* $L^{-1}$ & $0.10 \pm 0.05$ & $0.11 \pm 0.05$ \\
\hline
\end{tabular}

Data are presented as mean $\pm S D$, unless otherwise stated. BMI: body mass index; FEV1: forced expiratory volume in $1 \mathrm{~s}$; FVC: forced vital capacity; FEV6: forced expiratory volume in $6 \mathrm{~s}$; PEF: peak expiratory flow; FEF25-75\%: forced expiratory flow at $25-75 \%$ of FVC; FEF $55 \%$ : forced expiratory flow at $75 \%$ of FVC; TLCO: transfer factor of the lung for carbon monoxide; $K \mathrm{CO}$ : transfer coefficient of the lung for carbon monoxide; $V_{A}$ : alveolar volume; RVpleth: residual volume determined by whole-body plethysmography; FRCpleth: functional residual capacity determined by whole-body plethysmography; TLCpleth: total lung capacity determined by whole-body plethysmography; Raw: airway resistance; $\mathrm{s} G$ aw: specific airway conductance; $\mathrm{FRCmbw}$ : functional residual capacity determined by multiple-breath washout; VDF: Fowler dead space volume of the first breath; LCl: lung clearance index; Curv: curvilinearity; Scond: index of conductive ventilation; Sacin: index of acinar ventilation; Scond*: modified index of conductive ventilation; Sacin*: modified index of acinar ventilation.

However, for completeness we also included $\mathrm{FEF} 75 \%$ and $\mathrm{FEF} 25-75 \%$ in the online supplementary material. Finally, the PEF (online supplementary figure S6) showed excellent agreement with both KUSTER et al. [26] and Hankinson et al. [24], identifying similar independent contributors (sex, age, height) (table 2).

\section{Transfer factor and body plethysmography}

TLCO and TLCO/VA show the expected dependence on sex, height and age consistent with fragmented data from the literature $[4,7,25]$. In figure 2 it can be appreciated that TLCO shows a monotonous decrease over the entire age range with variability remaining almost constant throughout. Normal RVpleth/TLCpleth values (figure $2 \mathrm{~b}$ and online supplementary figure S13) were considerably smaller than those in the most recent ATS/ERS report [27]. The authors rightly pointed out that in the absence of more recent data, reference equations for lung volumes effectively refer to the ERS1983 reference equation for adults constructed from earlier equations resulting from plethysmographic and ventilation lung volume studies, and which potentially included smokers [6]. The RVpleth/TLCpleth obtained here were closer to RV/TLC data obtained in 1991 by ROBERTs et al. [7] using helium dilution by closed-circuit rebreathing and obtained in nonsmokers.

Finally, VA was consistently lower than TLCpleth and indeed paralleled TLCpleth over the entire range (figure 4), as could be expected [17]. It has been postulated that the ratio of TLC derived from a single- or 
TABLE 2 Coefficients for L, M and S to obtain predicted values, upper limit of normal and lower limit of normal for all studied parameters

\begin{tabular}{|c|c|c|c|c|c|c|c|c|c|c|c|}
\hline & \multirow[t]{2}{*}{$\mathrm{R}^{2}$} & \multicolumn{5}{|c|}{$M$ coefficients } & \multicolumn{4}{|c|}{ S coefficients } & \multirow{2}{*}{$\frac{\mathrm{L} \text { coefficient }}{\text { Intercept }}$} \\
\hline & & Sex & Height & Age & $\mathrm{Age}^{2}$ & Intercept & Height & Age & $\mathrm{Age}^{2}$ & Intercept & \\
\hline \multicolumn{12}{|l|}{ Spirometry } \\
\hline FEV $1 \mathrm{~L}$ & 0.80 & -0.684 & 0.0295 & -0.0249 & & -0.207 & 0.00937 & 0.00264 & & -3.87 & -0.628 \\
\hline FVC L & 0.79 & -0.765 & 0.0501 & -0.0217 & & -2.92 & 0.00377 & 0.00137 & & -2.86 & -0.108 \\
\hline $\mathrm{FEV}_{1} / \mathrm{FVC}$ & 0.32 & -0.0195 & -0.00229 & -0.00199 & & 1.28 & 0.00443 & 0.00350 & & -3.75 & 1.24 \\
\hline $\mathrm{FEV}_{6} \mathrm{~L}$ & 0.80 & -0.772 & 0.0476 & -0.0237 & & -2.44 & 0.00504 & 0.000556 & & -3.05 & -0.0563 \\
\hline $\mathrm{FEV}_{1} / \mathrm{FEV}_{6}$ & 0.28 & -0.0202 & -0.00224 & -0.00162 & & 1.26 & 0.00649 & 0.000341 & & -4.05 & 0.728 \\
\hline PEF L.S ${ }^{-1}$ & 0.66 & -2.98 & 0.0383 & & -0.000276 & 3.90 & -0.00495 & & 0.0000312 & -1.07 & 0.741 \\
\hline FEF75\% L.s ${ }^{-1}$ & 0.67 & -0.337 & & -0.0268 & & 2.74 & & 0.00502 & & -1.40 & -0.323 \\
\hline 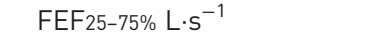 & 0.60 & -0.850 & & -0.0427 & & 5.49 & & 0.00785 & & -1.79 & -0.253 \\
\hline \multicolumn{12}{|l|}{ Carbon monoxide transfer } \\
\hline$T$ LCO $\mathrm{mmol} \cdot \mathrm{min}^{-1} \cdot \mathrm{kPa}^{-1}$ & 0.79 & -2.02 & 0.0947 & -0.0465 & & -4.42 & 0.00310 & 0.00583 & & -2.90 & -0.00441 \\
\hline $\mathrm{Kco} \mathrm{mmol} \cdot \mathrm{min}^{-1} \cdot \mathrm{kPa}^{-1} \cdot \mathrm{L}^{-1}$ & 0.30 & -0.0959 & -0.00402 & -0.00735 & & 2.62 & -0.00398 & 0.00423 & & -1.62 & 0.215 \\
\hline \multicolumn{12}{|l|}{ Body plethysmography } \\
\hline RVpleth L & 0.58 & & 0.0192 & & 0.000250 & -2.23 & 0.0134 & & -0.0000771 & -3.58 & 0.862 \\
\hline TLCpleth L & 0.69 & -0.993 & 0.0642 & & & -4.45 & 0.00477 & & & -3.02 & 0.437 \\
\hline $\mathrm{RV} / \mathrm{TLC}$ & 0.73 & 0.0355 & & 0.0000405 & 0.0000423 & 0.157 & & -0.0539 & 0.000356 & -0.137 & 1.11 \\
\hline Raw $\mathrm{kPa} \cdot \mathrm{s} \cdot \mathrm{L}^{-1}$ & 0.27 & & -0.00271 & -0.00634 & 0.0000656 & 0.837 & 0.00386 & 0.0108 & -0.000115 & -2.42 & 0.074 \\
\hline $\mathrm{sGaw} \mathrm{L} \cdot \mathrm{s}^{-1} \cdot \mathrm{kPa}^{-1}$ & 0.20 & & & 0.0282 & -0.000330 & 0.730 & & -0.0154 & 0.000160 & -1.31 & 0.587 \\
\hline \multicolumn{12}{|l|}{ Multiple-breath washout } \\
\hline$F R C_{m b w} L$ & 0.53 & -0.251 & 0.0525 & & & -5.67 & 0.00126 & & & -1.99 & 0.136 \\
\hline VDF/FRC & 0.18 & -0.00513 & -0.000635 & & & 0.161 & -0.00152 & & & -1.41 & 0.313 \\
\hline $\mathrm{LCl}$ & 0.52 & & & -0.0234 & 0.000480 & 6.34 & & -0.00130 & 0.000103 & -3.02 & -1.47 \\
\hline Curv & 0.30 & & & -0.00345 & 0.0000632 & 0.215 & & 0.00970 & -0.000170 & -1.03 & 0.993 \\
\hline Scond $\mathrm{L}^{-1}$ & 0.33 & & & 0.000331 & & 0.0188 & & 0.0166 & & -1.94 & 0.666 \\
\hline Sacin $\mathrm{L}^{-1}$ & 0.45 & -0.0153 & & -0.00296 & 0.0000471 & 0.132 & & 0.00653 & -0.0000486 & -1.31 & 0.279 \\
\hline Scond ${ }^{*} L^{-1}$ & 0.31 & & & 0.000459 & & 0.0216 & & 0.0149 & & -1.74 & 0.389 \\
\hline Sacin* $L^{-1}$ & 0.44 & -0.0156 & & -0.00286 & 0.0000454 & 0.128 & & 0.00733 & -0.0000625 & -1.30 & 0.323 \\
\hline
\end{tabular}

The value for sex is 0 for male and 1 for female subjects; height: $\mathrm{cm}$; age: years. $\mathrm{R}^{2}$ : Cox-Snell generalised $\mathrm{R}^{2}$; FEV 1 : forced expiratory volume in $1 \mathrm{~s}$; FVC: forced vital capacity; FEV6: forced expiratory volume in 6 s; PEF: peak expiratory flow; FEF75\%: forced expiratory flow at 75\% of FVC; FEF $25-75 \%$ : forced expiratory flow at 25-75\% of FVC; TLC0: transfer factor of the lung for carbon monoxide; Kco: transfer coefficient of the lung for carbon monoxide; RVpleth: residual volume determined by whole-body plethysmography; TLCpleth: total lung capacity determined by whole-body plethysmography; Raw: airway resistance; SGaw: specific airway conductance; FRCmbw: functional residual capacity determined by multiple-breath washout; VDF: Fowler dead space volume of the first breath; LCI: lung clearance index; Curv: curvilinearity; Scond: index of conductive ventilation; Sacin: index of acinar ventilation; Scond*: modified index of conductive ventilation; Sacin*: modified index of acinar ventilation. 

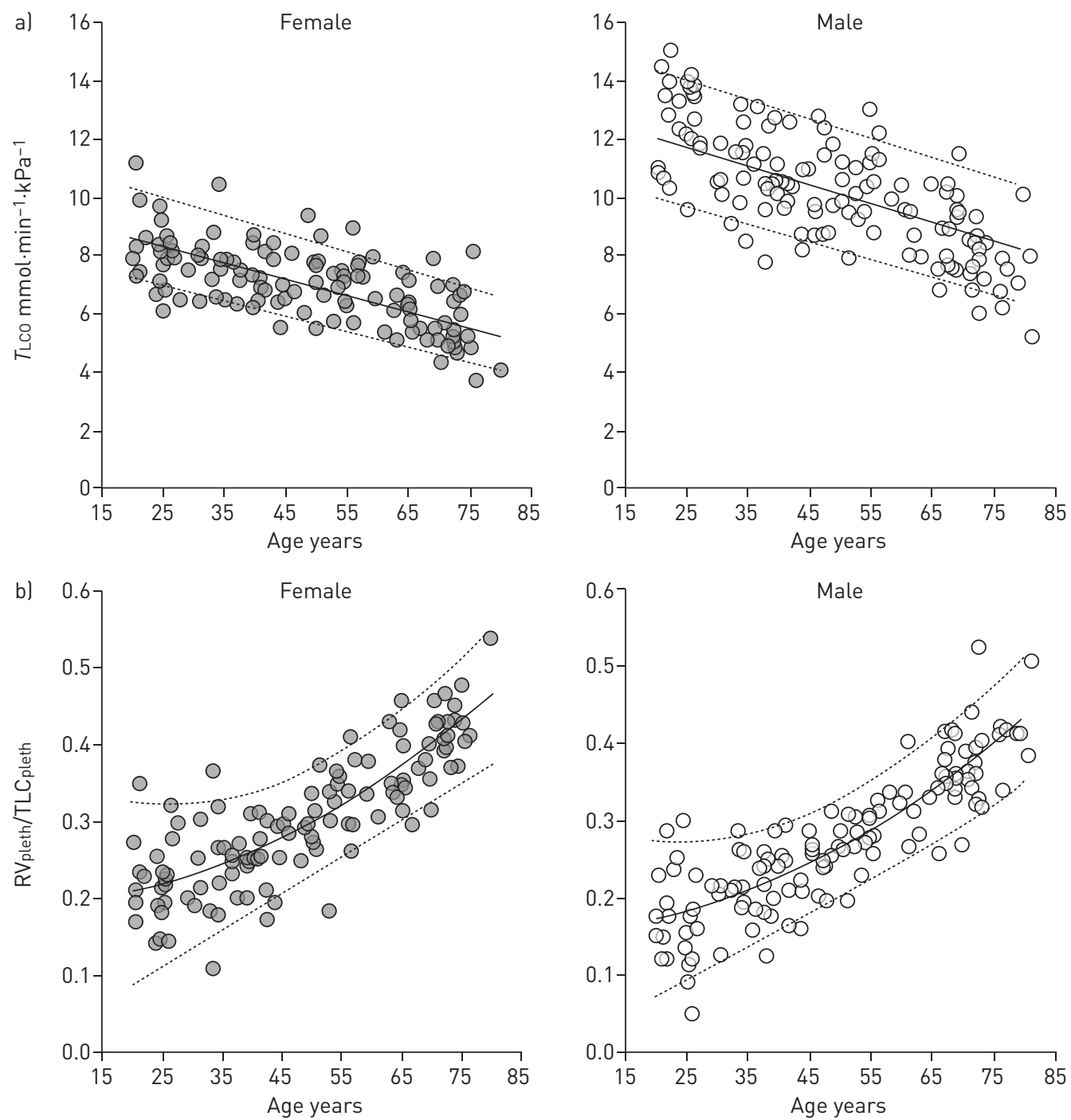

FIGURE 2 Scatterplots of a) transfer factor of the lung for carbon monoxide (TLCo), and b) the ratio of plethysmographic residual volume and total lung capacity (RVpleth/TLCpleth) versus age. Median (solid line), and lower and upper limits of normal (dashed lines) produced by the LMS model fit are also shown. Colour-coded versions of these figure panels, comparing with reference values from the literature, are in the online supplementary material.

multiple-dilution test could be a marker of incomplete ventilation distribution [33], potentially making VA/TLC a useful index in its own right. However, using TLCpleth instead of TLC by dilution (multibreath or rebreathing) adds complexity to the interpretation of $V \mathrm{~A} / \mathrm{TLC}$ pleth as a surrogate index, especially in obstructive patients. As a result of manufacturer-implemented corrections in the plethysmographic bodybox and the way the so-called thoracic gas volume (" $V \mathrm{tg}$ "; determined after the valve closure) is related to actual FRC, FRCmbw was chosen over FRCpleth as the preferred method to draw up reference equations for FRC. Nevertheless, when FRCpleth was compared with FRCmbw (figure 4), overall agreement was good, indicating general coherence of the data set. FRCmbw slightly decreased with age, via its dependence on height (which decreases with age; figure 1b), but age was not an independent predictor. This agrees with the very small age dependency obtained from dilution FRC in RoBERTs et al. [7], which is the same in both sexes. This contrasts with the 10 -fold greater age dependence in males versus females in the most used reference equations for FRC [27], probably due to a problem with summarised prior reference equations and the mixture of FRC values derived from ventilation and plethysmographic measurement [34].

To the best of our knowledge, there are no reference equations for airway resistance (Raw) obtained from body plethysmography and we can only compare the slight increase with age that we find in the age range $>45$ years with that obtained by $5 \mathrm{~Hz}$ forced oscillations [5]. The most noteworthy observation of our data set spanning 20-80 years is that there appears to be a minimum in Raw around the age of 45 years (online supplementary figure S14). Specific conductance ( $\mathrm{s} G \mathrm{aw}$ ) is seen to remain relatively constant up to 50-55 years, after which it 

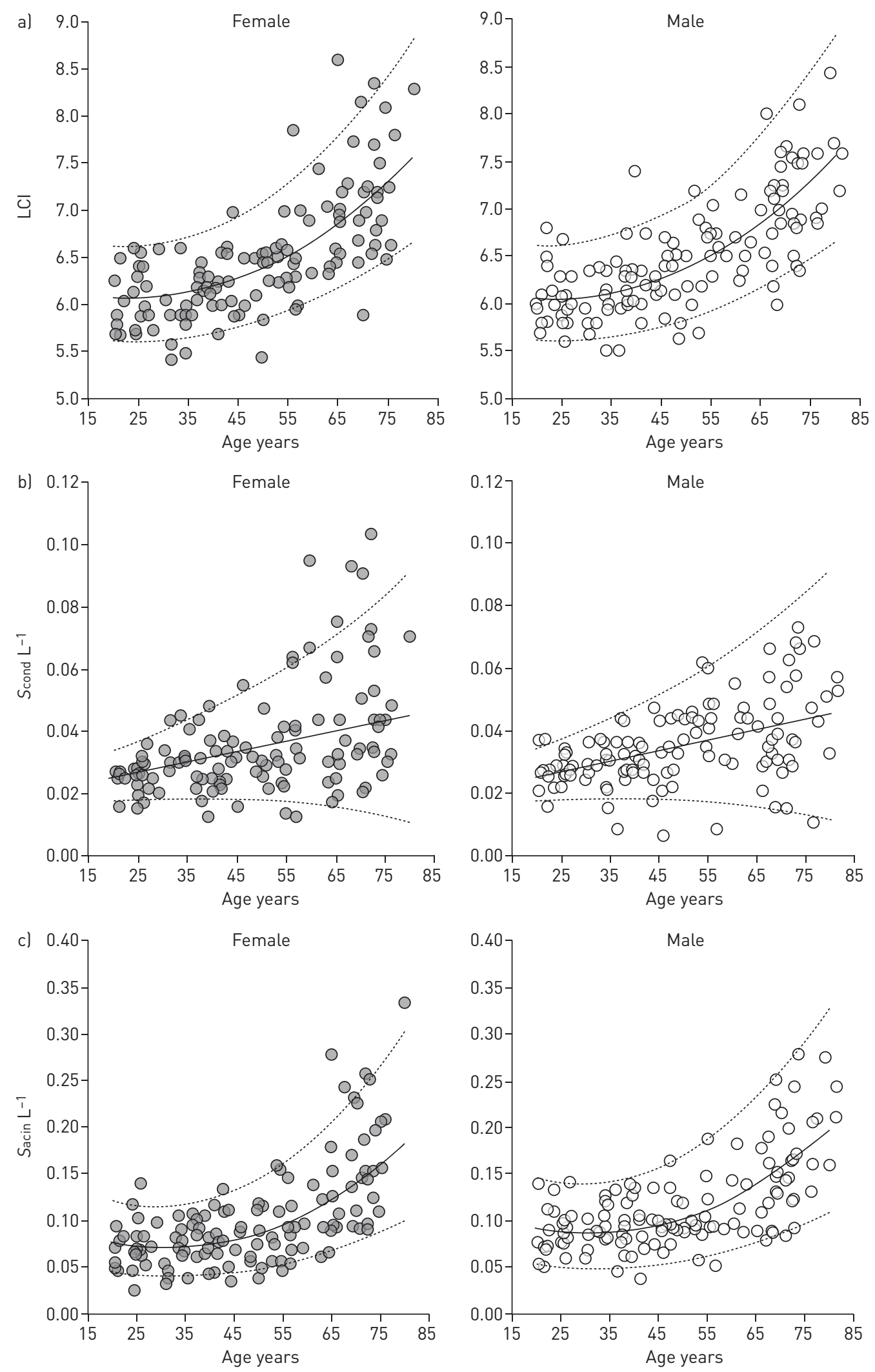

FIGURE 3 Scatterplots of standard indices derived from the multiple-breath washout test: a) lung clearance index (LCI), and b, c) indices of conductive and acinar ventilation heterogeneity (Scond, Sacin). Median (solid line), and lower and upper limits of normal (dashed lines) produced by the LMS model fit are also shown. 

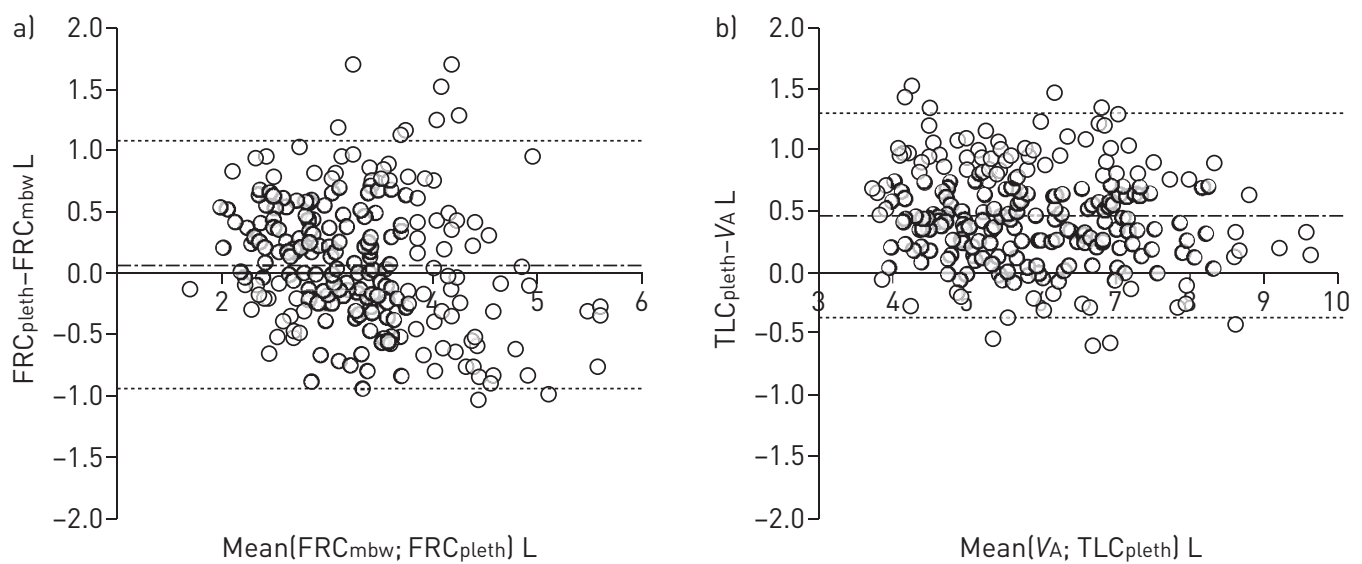

FIGURE 4 Bland-Altman plots of ventilated volumes obtained from a) the multiple-breath washout test (functional residual capacity (FRCmbw)) and b) the diffusing capacity test (alveolar volume (VA)) and their counterparts obtained from plethysmography (total lung capacity (TLCpleth) and FRCpleth)). Dashed-dotted and dashed lines indicate mean and $\pm 1.96 \mathrm{sD}$, respectively.

slightly deteriorates (online supplementary figure S15). No published reference values exist for Raw or sGaw covering the $20-80$ years range.

\section{MBW test}

First, using the raw data, we examined whether there was a link between LCI and Sacin and Scond, as was found to be the case in asthma patients [35]. In the present study, the "disease" driving Sacin and Scond values would be ageing, and indeed both appeared to correlate independently with LCI. An independent contribution from VDF as a fraction of FRC also contributed to an increased LCI. In this case, ageing per se was probably not the driving factor since FRC and VDF/FRC (online supplementary figures S16 and S17) do not show a significant dependence on age (table 2).

The reference equations for LCI, Scond and Sacin (figure 3 and table 2) essentially extend those previously obtained across two laboratories in a narrower age range (25-65 years) [15]. The greatest difference between that study and the present one is that in the age range up to 80 years, LCI and Sacin no longer vary linearly with age, but both increase more rapidly as age increases, resulting in an age-squared dependence. This implies that in the case of smoking-induced lung disease, which often appears later in life, increased acinar ventilation heterogeneity previously reported by our group may have been partly due to ageing [36]. Nevertheless, the average Sacin values observed in the COPD patient groups without emphysema $\left(0.295 \mathrm{~L}^{-1}\right.$; mean age 60 years) and with emphysema $\left(0.444 \mathrm{~L}^{-1}\right.$; mean age 68 years $)$ still largely exceeded the ULN obtained here in the corresponding 60-68 years range [36].

All three MBW indices of figure 3 are also characterised by a greater variability in the advanced age range, which is most marked for Scond (and its modified version $S$ cond ${ }^{*}$ ). The increase of average $S$ cond, as well as intersubject variability in Scond, with age is probably due to a greater intersubject heterogeneity of elastic properties of lung units larger than acini. The most likely explanation is loss of elastic recoil and changes in the elastic fibre network that are suggested to occur with ageing [37], bringing about a slight enlargement of respiratory bronchioles and alveolar ducts, without clear destruction of the alveolar walls. Probably, such structural changes are heterogeneously distributed over the lungs and do not occur to the same extent in all subjects. A recent computed tomography study also demonstrated age-dependent air trapping and airway remodelling in normal subjects aged 60-90 years, and the authors identified this to be a heterogeneous process [38].

\section{Limitations of the study}

Scaling down the number of subjects required, based on the $n=150$ per sex group proposed by QUANJER et al. [16] to obtain data in the range 5-90 years, we would have needed to include 15 subjects per decade and sex or 180 subjects in total. For lung volumes, the recommended number by SтоскS et al. [27] to obtain adult reference equations is 100 for men and women. One could argue that the recommended numbers may not hold for all other indices, yet the reasoning behind the recommended sample size in QUANJER et al. [16] was based on $\mathrm{Z}$-scores, which should in principle apply to all indices measured on normal subjects. Nevertheless, we accept that there is something arbitrary about the choice of a criterion for the number of subjects. Here, we refer to our data set (with a homogeneous distribution over the entire age range and a low number of outliers) and the overall agreement with predictions from other studies wherever available, 
thus attesting to the adequacy of the number of subjects studied here. Another limitation concerns the equipment used, which mainly pertains to indices derived from MBW. While MBW indices Scond and Sacin are less sensitive to equipment dead space than LCI [15], all three indices are sensitive to the gas used. This implies that the absolute values provided by the reference equations may not be blindly applied to other devices or laboratories elsewhere. However, the observed sex or age dependence of these indices and their variability should be similar, and can be borne in mind when selecting a group of healthy subjects locally in the validation phase of a newly installed MBW device in any given laboratory. A final limitation of the study is that the reference equations cannot be readily used for subjects of ethnicity other than Caucasian or for Caucasian subjects outside the normal length and weight ranges.

In conclusion, we obtained reference equations for most lung function indices currently implemented in a lung function laboratory with a keen interest in pulmonary research. For some variables (Raw, sGaw, VDF/FRC), no such reference data existed; for others (RV/TLC, FRC), existing reference equations were judged inadequate, and for ventilation distribution data, these showed an accelerated deterioration (LCI, Sacin) and increased variability (Scond) beyond 60 years.

\section{References}

1 Quanjer PH, Stanojevic S, Cole TJ, et al. Multi-ethnic reference values for spirometry for the 3-95-yr age range: the Global Lung Function 2012 equations. Eur Respir J 2012; 40: 1324-1343.

2 Global Lung Function Initiative. http://www.lungfunction.org/component/content/article/85-equations-and-tools/ equations/150-gli-2012-desktop-software-for-large-data-sets.html Date last updated: March 26, 2013. Date last accessed: April 5, 2015.

3 Verbanck S. Physiological measurement of the small airways. Respiration 2012; 84: 177-188.

4 Thompson BR, Johns DP, Bailey M, et al. Prediction equations for single breath diffusing capacity (Tlco) in a middle aged Caucasian population. Thorax 2008; 63: 889-893.

5 Schulz H, Flexeder C, Behr J, et al. Reference values of impulse oscillometric lung function indices in adults of advanced age. PLoS One 2013; 8: e63366.

6 Quanjer PhH, ed. Standardized lung function testing. Report Working Party "Standardization of Lung Function Tests”. Bull Eur Physiopathol Respir 1983; 19: Suppl. 5, 1-95.

7 Roberts CM, MacRae KD, Winning AJ, et al. Reference values and prediction equations for normal lung function in a non-smoking white urban population. Thorax 1991; 46: 643-650.

8 Downie SR, Salome CM, Verbanck S, et al. Ventilation heterogeneity is a major determinant of airway hyperresponsiveness in asthma, independent of airway inflammation. Thorax 2007; 62: 684-689.

9 Farah CS, King GG, Brown NJ, et al. Ventilation heterogeneity predicts asthma control in adults following inhaled corticosteroid dose titration. J Allergy Clin Immunol 2012; 130: 61-68.

10 Verbanck S, Schuermans D, Paiva M, et al. Small airway function improvement after smoking cessation in smokers without airway obstruction. Am J Respir Crit Care Med 2006; 174: 853-857.

11 Robinson PD, Lindblad A, Gustafsson PM. Comparison of the utility of multiple breath inert gas washout parameters in cystic fibrosis. Thorax 2010; 65: 659.

12 Verbanck S, Paiva M, Paeps E, et al. Lung clearance index in adult cystic fibrosis patients: the role of convection-dependent lung units. Eur Respir J 2013; 42: 380-388.

13 Hellinckx J, Cauberghs M, De Boeck K, et al. Evaluation of impulse oscillation system: comparison with forced oscillation technique and body plethysmography. Eur Respir J 2001; 18: 564-570.

14 Oostveen E, Boda K, van der Grinten CP, et al. Respiratory impedance in healthy subjects: baseline values and bronchodilator response. Eur Respir J 2013; 42: 1513-1523.

15 Verbanck S, Thompson BR, Schuermans D, et al. Ventilation heterogeneity in the acinar and conductive zones of the normal ageing lung. Thorax 2012; 67: 789-795.

16 Quanjer PH, Stocks J, Cole TJ, et al. Influence of secular trends and sample size on reference equations for lung function tests. Eur Respir J 2011; 37: 658-664.

17 Pellegrino R, Viegi G, Brusasco V, et al. Interpretative strategies for lung function tests. Eur Respir J 2005; 26: 948-968.

18 Miller MR, Hankinson J, Brusasco V, et al. Standardisation of spirometry. Eur Respir J 2005; 26: 319-338.

19 MacIntyre N, Crapo RO, Viegi G, et al. Standardisation of the single-breath determination of carbon monoxide uptake in the lung. Eur Respir J 2005; 26: 720-735.

20 Wanger J, Clausen JL, Coates A, et al. Standardisation of the measurement of lung volumes. Eur Respir J 2005; 26: 511-522.

21 Stuart-Andrews C, Kelly C, Sands S, et al. Automated detection of the phase III slope during inert gas washout testing. J Appl Physiol 2012; 112: 1073-1081.

22 Verbanck S, Paiva M, Schuermans D, et al. Acinar and conductive ventilation heterogeneity in severe CF lung disease: back to the model. Respir Physiol Neurobiol 2013; 188: 124-132.

23 Lum S, Stocks J, Stanojevic S, et al. Age and height dependence of lung clearance index and functional residual capacity. Eur Respir J 2013; 41: 1371-1377.

24 Hankinson JL, Odencrantz JR, Fedan KB. Spirometric reference values from a sample of the general U.S. population. Am J Respir Crit Care Med 1999; 159: 179-187.

25 Miller A, Thorton JC, Warshw R, et al. Single breath diffusing capacity in a representative sample of the population of Michigan, a large industrial state. Am Rev Respir Dis 1983; 127: 279-287.

26 Kuster SP, Kuster D, Schindler C, et al. Reference equations for lung function screening of healthy never-smoking adults aged 18-80 years. Eur Respir J 2008; 31: 860-868.

27 Stocks J, Quanjer PH. Reference values for residual volume, functional residual capacity and total lung capacity. ATS Workshop on Lung Volume Measurements. Official Statement of The European Respiratory Society. Eur Respir J 1995; 8: 492-506. 
28 Newbury W, Crockett A, Newbury J. A pilot study to evaluate Australian predictive equations for the impulse oscillometry system. Respirology 2008; 13: 1070-1075.

29 Pelzer AM, Thomson ML. Effect of age, sex, stature, and smoking habits on human airway conductance. J Appl Physiol 1966; 21: 469-476.

30 Krell WS, Agrawal KP, Hyatt RE. Quiet-breathing vs. panting methods for determination of specific airway conductance. J Appl Physiol Respir Environ Exerc Physiol 1984; 57: 1917-1922.

31 Vandevoorde J, Verbanck S, Schuermans D, et al. FEV1/FEV6 and FEV6 as an alternative for FEV1/FVC and FVC in the spirometric detection of airway obstruction and restriction. Chest 2005; 127: 1560-1564.

32 Quanjer PH, Weiner DJ, Pretto JJ, et al. Measurement of FEF25-75\% and FEF75\% does not contribute to clinical decision making. Eur Respir J 2014; 43: 1051-1058.

33 Roberts CM, MacRae KD, Seed WA. Multi-breath and single breath helium dilution lung volumes as a test of airway obstruction. Eur Respir J 1990; 3: 515-520.

34 Verbanck S, Vandevoorde J, Vincken W. Internal consistency of reference equations. Eur Respir J 2011; 38 : 233-234.

35 Verbanck S, Paiva M, Schuermans D, et al. Relationships between the lung clearance index and conductive and acinar ventilation heterogeneity. J Appl Physiol 2012; 112: 782-790.

36 Verbanck S, Schuermans D, Meysman M, et al. Noninvasive assessment of airway alterations in smokers: the small airways revisited. Am J Respir Crit Care Med 2004; 170: 414-419.

37 Janssens JP, Pache JC, Nicod LP. Physiological changes in respiratory function associated with ageing. Eur Respir J 1999; 13: 197-205.

38 Bommart S, Marin G, Bourdin A, et al. Computed tomography quantification of airway remodelling in normal ageing subjects: a cross-sectional study. Eur Respir J 2015; 45: 1167-1170. 